\title{
A Reconsideration on the Theory of Beauty: Selected Definitions, Concepts and Views on the Topic (Part I)
}

\author{
Iulia-Adina Lehene ${ }^{1 *}$ \\ 1 Doctoral School, Technical University of Cluj-Napoca, 40020 Cluj-Napoca, 15 Constantin Daicoviciu, Romania \\ * Corresponding author, e-mail: iulia_lehene@yahoo.com
}

Received: 30 May 2018, Accepted: 28 October 2020, Published online: 18 November 2020

\begin{abstract}
This paper is the first part of our work that aims to rethink the concept of beauty as close as possible to its essence, in the way it integrates the science of aesthetics with the field of construction. The study may be further used, within other theoretical and practical works, for physically reflecting the definition of beauty in areas such as architecture, civil engineering or urban planning, and to support professionals in designing and building beautiful objects and constructions.

It is important to note at this point that the assumption is that there must be a particular original aspect related to beauty that leads a human-made object to success, which needs to be further identified. The approach to the concept of beauty is through a broadly philosophical approach and partly through the areas mentioned above.

The initial study aims to frame the niche of the beauty within the field of aesthetics, continuing the guidelines provided in the Architecture School of Cluj-Napoca. It further lists relevant concepts raised through the discussions, the arguments defining beauty, and comprises a brief presentation of the views of beauty from a selection of aestheticians accompanied by short observations about our understanding on beauty, and the conclusions of this preliminary study. We considered it essential to present a selection of concepts and views on beauty so to further apply them to constructions, and later to the presentation of our own reconsidered theory.
\end{abstract}

Keywords

aesthetics, beautiful, constructions, evolution, creativity

\section{Introduction}

Along with the daily struggle to build beautiful buildings and cities, we sometimes forget to take a break from production and to look back, to observe the path behind us and synthesise the most important aspects that we should take into account in achieving the goal of building the beautiful. ${ }^{1}$ Let us observe the principles we try to produce this beautiful by, the other old and new principles that exist in the field, and whether our roadmap can be corrected to achieve a higher performance. For this, we need to open our minds and examine how others define beauty, but also to strengthen our vision of it.

One of the reasons for starting the research on this topic is precisely a lower availability of the synthetic bibliographic references of what constitute a building's beauty.

1 The application of the aesthetic complex in architecture, civil engineering and urbanism is the subject of a separate work, but some of its aspects are mentionned in the Section 2.

\subsection{The niche definition of the aesthetics}

This part of the study targets an understanding of the aesthetic concept, meaning the notion of beauty.

The definition of aesthetics from the Dictionary of General Aesthetics is useful for guiding the study: aesthetics is "a philosophical discipline that studies the essence, the laws, the categories and the structure of that human attitude towards reality, characterised by the reflection, contemplation, valorisation and creation of specific traits of the objects and of the processes from nature, society and consciousness or of the human (artistic) creations" (Achiţei et al., 1972:p.110). This definition, very close to the niche studied here, does not contain the word beauty; however, the it is found in the definition given by the Explanatory Dictionary of Romanian:

- aesthetics is "a science that studies the laws and the categories of art, considered to be the highest form of creation and reception of the beautiful; a set of matters regarding the essence of the art, 
its relations with the reality, the method of the artistic creation, the criteria and the genres of the art" (Romanian Academy, 2000).

Here, art is introduced as the central concept, which is nevertheless treated only tangentially in the present work. The niche on which the study focuses is beauty, and we provide a negotiated definition of it as: aesthetics is the science that studies the justification or rationale by which an object, of art or not, is found to be beautiful, what makes it to be beautiful. This science is based primarily on contemplation.

One of the guiding definitions of aesthetics for the present paper follows: "aesthetics is the essential feature of what is enjoyed by a sufficiently large percentage of society to be easily identifiable, on psychological reasoning, at specific historical moments" (Moldovan, 1993:p.94).

Within the Cluj-Napoca Architecture School, the architect Mircea Sergiu Moldovan highlights three possible purposes of an aesthetic work:

1. the expression of the author's synthesis, or based on the existing situation;

2. a forecast;

3. a collection of "notions, configurations and elements" valorised within the academic framework and subsequently exploited by specialists (architects, engineers, urbanists) (Moldovan, 1993:p.72).

However, the present paper, developed under the aesthetics' umbrella, intends a synthesis of the three variants issued by Moldovan: it focuses on the selective presentation of the theoretical heritage, the exposition of our particular vision and the shaping of a reconsidered formula as a guide in the quest for the beautiful.

\subsection{Selected concepts}

Besides helping to shape the framework in which the present study takes place, a selection of concepts is further presented to encourage the reader to meditate on the topic of beauty. Moldovan also discussed the majority of these concepts in the cited work, but our comments, emphases and additions have been added:

- Creation: In practice, the success of man's creation is understood in many ways. If the public is the one who ranks it, then aesthetic means intelligent (Stendhal), political (Nodier), force (Nietzsche), mediocrity (Ingres, Baudelaire), hazard (Cournot) (Moldovan, 1993:p.50). Passing the concept of success through our filters, we can add meanings such as: beautiful, attractive, exciting; challenging reasoning, the senses, socially, culturally, economically; intriguing, futuristic, ecological, durable, invincible, conciliative, stimulating, new, different, random, neutral, comfortable.

- The valuable creation is not a copy of another valuable creation, but it is the unique and personalised response to a real human need that is the need for the aesthetic value (Moldovan, 1993:p.116).

- The process of creation: Moldovan says: "The fact that the process of creation, contemplation or interpretation is difficult to live again, rebuild, or share has accredited the image of the unexplainable spontaneity and irrationality of the creativity" (Moldovan, 1993:p.116). These are the steps we believe the process of creation follows: artist $\rightarrow$ creation $\rightarrow$ useful creation from any point of view not only functional, $\rightarrow$ beautiful, useful creation $\rightarrow$ intelligent, beautiful, useful creation $\rightarrow$ intelligent, beautiful, useful creation able to evolve or to assimilate the evolution.

- Artwork: Its author attempts to portray an idealised or innovative version of reality, of the imagination or human needs.

- Creative authenticity: It exists in the globe found above the artist's universe or above the creator of beautiful objects that he/she protects to preserve his/ her authenticity. The artist continues to strengthen this authenticity by discovering and emphasising the outline of their creative force and inspiration.

- The creative genius: Edgar Allan Poe said that "the genius would be more a later judgment than a creative diary" (Moldovan, 1993:p.46). We add that the creative brilliance consists of identifying those ultimate and universal criteria or attributes that gives success to the creative effort, assigning the recognition of a beautiful object.

- The creative contemplation: Victor Basch clearly observed that creative power is materialised only through contemplation (Basch, 1930:pp.377-378). We can shape the path to obtaining the aesthetic value through the following phases: observation $\rightarrow$ creation $\rightarrow$ contemplation $\rightarrow$ critique $\rightarrow$ aesthetics. If one starts with observing the environment, they can continue with the act of creation as imitation, inspiration or negation of what they see. Next, a second person contemplates the product of creation to criticise it and, following the judgment of value, 
to rank it aesthetically, highlighting its essence. Then the process of creation crosses these steps: creation $\rightarrow$ contemplation $\rightarrow$ analysis $\rightarrow$ comparison $\rightarrow$ critique $\rightarrow$ essentialisation $\rightarrow$ aesthetics.

- Industrialisation: Most of the people easily recognise an industrialised item and call it aesthetic. This is why the industrialization is a trap for aesthetics. And yet if something is widely recognised, it does not necessarily mean that it has aesthetic qualities, given that many beautiful objects are often not recognised by the public either soon or ever. Sooner or later in engineering, architecture and urban planning, at least partly, "the technical and industrial art replacements" (Moldovan, 1993:p.91) become necessary due to the efficiency (beyond their limitations) of CAD software in design and execution. The artist-engineer's brilliance is reflected in how they succeed in overcoming the limitations of the technology and industry. The latter two can be optimally exploited when the creativity, originality and innovation have been clearly articulated before moving to the phase of the concept's technicalisation or industrialisation.

- The systematic methods of knowledge: The knowledge possesses many methods, some of which are referred to, according to Mircea Sergiu Moldovan's inventory from his Aesthetics Course published in 1993 (Moldovan, 1993:p.67):

- induction and deduction; analysis, synthesis and comparison;

- experiment and psychoanalysis;

- phenomenology, contextual and existentialism;

- structuring and structural stylistics; "the quantitative, informational, cybernetic, semiotic methods".

- The ideal: The ideal is a level where is found and maybe recognised a thing that, by its very nature, cannot be understood or perfectly assimilated. It can be sought, but success lies in the continuous journey, not in arriving at the end and thus stopping. One can aspire to the ideal and use it as a direction.

- Theories' evolution: The questions about why theories are evolving, why ideas change, why the trends, the tendencies, the patterns flow; why is the new often over-appreciated. The answer is because humankind, consciously or not, is in a continuous quest for perfection, for the ideal, for what satisfies all his or her needs so to arrive implicitly to the stage of psychological plenitude. Why humans appreciate the new with the hope and the impression that they will achieve, in this way, perfection. The perpetuation of this process is due to the attempt to satisfy some needs, while others should be met. The succedent or the surrogate procrastinate the satisfaction of their real needs (Moldovan, 1993:p.113).

- Thebeautiful: It is "the basic aesthetic phenomenon and the central category of aesthetics" (Morar, 2003:p.56). There is, besides the beautiful, the graceful and the sublime as positive aesthetic categories, while the negative aesthetic categories are the ugly and the tragic. Which leads to the question of why there are also negative aesthetic categories - is it not the aesthetic concept already pointing to the positive sphere? Looking for a definition of the aesthetic category, the General Aesthetics Dictionary defines the aesthetic categories as "types of emotional reactions that represent instruments of the world's aesthetic knowledge [...]. The crystallisation of the notion is the result of the process of an initial established relationship [...] between the affectivity of the contemplative human subject and the contemplated object" (Achiţei et al., 1972:p.63). The next question that arises is why artists, and not just in latter times, transmit brutality instead of sensitivity; why do they offer examples of artwork belonging to the negative aesthetics, instead of only to the positive aesthetics? Perhaps it is because the generation and transmission of positive emotional reactions stem from weakness, from an unsatisfied need of the one who creates and, similarly, of the contemplative human subject. Likewise, the aesthetic objects generating adverse affective reactions at least imply that those creators or contemplators are not weak but strong. It can be deduced from this that the nature of the effects produced by the objects someone created betrays the creator's position on Maslow's (1943) pyramid and, thus, his evolutional level.

The thinkers were split into two categories by their vision of beautiful: the objectivists who claimed that beautiful is an appropriation of objects independent of the observer subject, and the subjectivists who argued that beautiful is an appropriation owned by the objects as it is observed and declared by the observer. Sometimes, the subjectivist aestheticians have said that beauty is in the eye of the one who sees the beauty in one thing (see Hume, 1742). We choose to belong to the category of the objective aesthetics, and the arguments put forward support this. 
The beautiful is "the universal object of aesthetics", and the sublime is "the augmentative extension of the beautiful" (Morar, 2003:p.58). Beauty is the quality of objects that validate their belonging to art or not. All beautiful art objects reveal the same thing: spiritual validity (Beardsley, 1962:p.622). The beauty is what likes no matter who sees it. Umberto Eco believed that "beautiful was something which, if it were ours, it would cheer us, but it remains so if it belongs to someone else too" (LatteralMente, 2002):

- The aesthetic attitude: It consists in the fundamental human inclination to perceive the surrounding reality through senses, generating emotional and intellectual reactions in their consciousness. Although it is distinct from other human attitudes, namely the utilitarian, ethical, philosophical, scientific, political and religious attitudes, that one is manifested fully only in conjugation with the others.

- The aesthetic judgment: It is the process accompanied by its result by which one valorises an object or a work aesthetically in terms of their taste, culture and values system. The objectivity of the aesthetic judgment is made considering the constitutive elements and the structure of the object in question.

- The aesthetic experience: It represents the process and the result of one's accumulation of aesthetic knowledge, obtained by the direct interaction between the subject and the object. This involves the contact of the subject with the object, meditation, impressing and appraising the aesthetic values of the object.

- Taste: It is a sense that manifests spontaneously and through which a person expresses predominantly intuitively their aesthetic attitude depending on their psychic structure, level of evolution and culture.

\section{The matter of the beautiful}

There have been many thinkers, artists and professionals who have delivered a variety of theories about aesthetics in general and about the urban aesthetics in particular, or who create items according to their ideologies of aesthetics and beauty. To create an overview, they are important to study because they are all correct from one point of view or another.

The unification of these theories and the addition of the entire list of positive and negative determinants lead to a formula of the aesthetics success or, if not, at least to an exhaustive list of determinants. This formula, conceptually, is remarkably similar to what, in urban planning, the town planning regulations are because they also aim to achieve the highest possible quality of cities. Unfortunately, often, none of these leads practically to success. The theory presented in the article that will be published soon as the second part of this paper starts from the first hypothesis that the reason why so often the aesthetic failure occurs in practice belongs to an original factor that is overlooked or is not given the appropriate weight. The second hypothesis of the theory is that the neglected original factor is the level of evolution where is situated the human, thus society. This is an exponential factor of the formula.

The third hypothesis is that the level of human evolution is parallel to Maslow's (1943) scale. Maslow (1943) divided human needs into five categories or steps:

- physiological,

- security,

- affiliation,

- esteem needs

- personal plenitude.

The more satisfied these steps are within the individual, the more evolved with, the higher the capacity to understand themselves and the world in which they live. The fourth hypothesis of the theory is that the evolved individual has the ability to do anything at a higher level, even to understand beauty, and to apply it successfully. For example, to be able to design beautiful structures and buildings and able to build beautiful cities.

If one is not on a higher stage of their evolution, satisfying other determinants is impaired, and consequently, the quality of the obtained product is compromised.

The exposition in this paper focuses on the median between the philosophical aesthetics on the one hand and the engineering, architectural and urban aesthetics on the other. ${ }^{2}$

\section{The concept of beautiful from a series of aestheticians}

Some 23 thinkers, philosophers and aestheticians, acknowledged across the centuries as reference personalities on the matter of beautiful towards human objects were selected. Their visions are exposed briefly below in chronological order, being accompanied by our comments aiming to support our vision, which is extensively presented in the article that will be published soon as the second part of this work. The primary support we used was the pragmatic, and oriented toward our topic work of Wladyslaw Tatarkiewicz, History of Aesthetics (1978), while complimentary support

2 The development of the matter of the buildings aesthetics will be achieved in a separate paper. 
was Katharine Gilbert and Helmut Kuhn's History of Aesthetics (1972). Nine more thinkers' visions were added from other sources to round up the picture of the beautiful perceived in the process of creating and assessing the human objects, from the $4^{\text {th }}$ century BCE to the current day:

- Socrates (470-399 BC): In the Socratic vision, art imitates nature; beautiful is an idealisation in the art of nature, the art can express besides a visual, physical beauty also a spiritual beauty. Socrates argued that the beauty of an object comes from the utility of that one; it exists when the object serves its purpose or is missing when the object does not prove its usefulness. Having a functionalist view, Socrates says that what is right is also beautiful, the meaning of the beautiful and the good merge (Tatarkiewicz, 1978a:p.157-160). Understanding how nature is made-up and functions, and translating these into human works represents a superior way of driving life, by adding more value to it.

- Democritus (460-379 BC): Among the Ionian philosophers, he was "the most convinced materialist, deterministic and empiricist" (Tatarkiewicz, 1978a:p.139); he was also hedonistic and judged everything by the ability to produce pleasure. Democritus' opinion is that art imitates nature in its way of acting, the beautiful is a conclusion of the contemplation of objects or works (Tatarkiewicz, 1978a:p.145) and he sustained the triad contemplation-beautiful-joy (Gilbert and Kuhn, 1972:p.29).Hemade thepoint that"weareinclined toward beautiful things" (Tatarkiewicz, 1978a:p.145). If Democritus believed the man be inclined towards beautiful things, we deduce that supporting our theory of beauty, the observer is responsible for identifying or not the beautiful in the things, according to the capacity owned by each observer.

- Plato (427-347 BC): The ancient Greek culture, also called Platonic, was based on the contemplation of the good and the beautiful, concepts often considered synonyms. The process of contemplating the beautiful was giving value to life (Tatarkiewicz, 1978a:p.172). For Plato, the beautiful brought admiration, delight, appreciation, and satisfaction, not just that which was producing pleasure to look at or listen to (Tatarkiewicz, 1978a:p.173). His concept of beauty, in addition to objects and beings, included virtues; divided into three categories: aesthetics, morals and cognitive (Tatarkiewicz, 1978a:p.174). Plato revealed a conversation between Socrates and Hippias in his writing Hippias Maior that opens the matter of the beautiful through the perspective of what makes it to be so, respectively of what makes it to look like so (Plato, 1976:pp.59-60). To this, we add that things seem like the observer succeeds through his psychological, intellectual, philosophical and spiritual ability to perceive it, but that does not change the real dimension of the beautiful owned by that thing (see also Gilbert and Kuhn, 1972:p.47).

- Aristotle (384-322 BC): Aristotle's original definition of beauty is as follows: "It is what is preferred for its intrinsic qualities [...] is good" (Tatarkiewicz, 1978a:p.244). The beautiful was encompassing what is right and pleasant (Gilbert and Kuhn, 1972:pp.85-90), but beautiful was different than the useful. It is the verdict of a decision-making act (preferably), the observer decides, whether it evaluates the work as beautiful or not. Beauty is a mass-recognised quality; it is "worthy of all praise" (Tatarkiewicz, 1978a:pp.207-236). Aristotle said: "the idea of beautiful is different at every age". This supports our theory of beauty, claiming that as man moves from one stage of evolution to another, he perceives and understand the beautiful differently, more profoundly.

- Vitruvius (81 BC-15 AD): He stated that the beautiful and the useful are equally crucial in architecture. There is a formally beautiful and functionally beautiful. The beautiful is a property of things to satisfy the eye with the sight. The beauty of a thing is achieved by symmetry, eurythmy (rhythm), the harmony of the parts and their proper proportions. For Vitruvius, nature and especially the human body was an example of beauty for whoever wants to create beautiful things - he supported the imitation of nature. He also said that the beautiful had a social component whereby something must be adapted to people's needs and customs. Vitruvius brought into consideration the necessity of something to be also useful to be considered beautiful (Tatarkiewicz, 1978a:p.71). Here we add that the process of creating a thing should already consider the needs and the level of evolution of the person to whom the object is intended for, to validate the beauty of that object.

- Plotin (204-270 AD): Rejecting the earlier classical definition of the beautiful, he became the founder of the Neoplatonism. He considered that the beautiful is not the direct and immediate consequence of symmetry, 
nor necessary fitting the parts of the entire, but that the beautiful depends on "the soul, the spiritual blowing" (Gilbert and Kuhn, 1972:pp.116-119), the emotional impression that the object transmits to the observer. He said that "only the soul that became beautiful can see the beauty" (Tatarkiewicz, 1978a:p.465) and that "even the soul would not see the beautiful if it was not beautiful itself. Let it firstly become godly and beautiful whoever tries to peek the beauty with the sight" (Tatarkiewicz, 1978a:p.474). He introduced the concept of emanation, which is the beauty that spreads around. Plotin is the first to express the need for the observer to have reached a level of evolution necessary to be able to see, to understand and to appreciate the beauty of one thing.

- St. Augustine (354-430 AD): He studied ancient philosophy, was an objectivist aesthetician, considering that the beauty is found in things, and the observer is about to discover it (Tatarkiewicz, 1978b:p.76). He said that, since beauty resides in the things, these like to the sight and they are not beautiful because they like to the sight. The beauty of a thing was, according to St. Augustine, the result of several factors: the harmonious cooperation of the parts of the whole, unity, order, the right measure and proportion, shape, the appropriate chromaticity. Beautiful stems both from a mathematical relationship, according to its position as an aesthetician, and from an inner beauty, according to its position as a theologian. He put, to a certain extent, the sign equal between beautiful and good, because he was saying that what had measure, order and the right form was also good (Tatarkiewicz, 1978b:p.77). It is interesting to notice here that the beautiful is admitted to represent more than what is visible and physical; it also has an inner, metaphysical component.

- Pseudo-Dionysius (6 ${ }^{\text {th }}$ century AD): The good and the beautiful coincided, according to Pseudo-Dionysius. Having a theological formation, he sought the origin of the beautiful in God. He introduced, through his conception over the beautiful, the term superplatonism that consists in the view that the beautiful is the cause, the substance, the principle, the pattern, the measure and the purpose of all relationships, owning a supreme value (Tatarkiewicz, 1978b:p.46). Also, the absolute beauty, considered to be divine, emanates radiations producing a perceptible earthy beautiful. He had a monistic view over the beautiful, considering that only the divine beautiful exists and that is the absolute beautiful (Tatarkiewicz, 1978b:pp.47, 49). He moved the concept of beautiful from the experience zone to speculation and added that the beautiful is light (Tatarkiewicz, 1978b:p.50). We also believe beauty to be a component and reflection of the Divine, as each thing encompasses a part of it from its Origin.

- St. Thomas Aquinas (1225-1274): Thought that the beautiful things were those which produce pleasure, namely pleasure through their sight; sight comprising all the senses (Gilbert and Kuhn, 1972:p.131). The beautiful for him was different from the utility because a beautiful thing should not necessarily be useful, and vice versa (Tatarkiewicz, 1978b:p.354), and different from the good because the initial one results from pleasure and is a superficial trait, while the latest from contemplation and is an intensely owned trait (Tatarkiewicz, 1978b:p.355). He believed that the beautiful is in proportion-integrity, conformation-perfection and clarity (Tatarkiewicz, 1978b:p.362). Besides the theories that directly support our vision, different opinions, like St. Thomas Aquinas, also help in developing the judgement over what is and what is not beautiful.

- Leon Battista Alberti (1404-1472): He had a classic view on beauty, defining it as "harmony, the coherent structure of the parts, the perfect proportion" (Gilbert and Kuhn, 1972:p.176). For a harmonious whole, there is only one right solution to harmonise and optimise the components (Tatarkiewicz, 1978c:p.135). To possess successful qualities, a composition is based on a certain proportion of the components, and the three proportions that he appreciated were: arithmetic, geometric and musical $\left(\frac{a}{b}+\frac{m-a}{b-m}\right) \quad$ (Tatarkiewicz, 1978c:p.135).

The laws that define the optimal proportions are given by nature; the beautiful is "a goal for the man" (Tatarkiewicz, 1978c:p.135). He was an objectivist aesthetician. The beautiful is the proper result of the creative intent; it is obtained by creating compatibility between the form and the content (Tatarkiewicz, 1978c:p.136). Associating to beautiful concepts like harmony, compatibility or proper, optimal, it shifts its meaning more towards perfection. Perfection, as it will be presented in the article that will be published soon as the second part of this work, a permanent aim of the process an evolving human finds himself in. 
- Leonardo da Vinci (1452-1519): His vision of beauty is concentrated into three statements: The beautiful is obtained by mimicking nature with high precision. "Not always what is beautiful is also good." Different bodies may have different beauties and at the same time identical grace, the latter representing the result of these aesthetic qualities of a thing (Tatarkiewicz, 1978c:p.206). He had a concern about how people perceive nature, the environment, about the "descriptive natural science, and about the descriptive psychology of the perception" (Tatarkiewicz, 1978c:p.207). Da Vinci's ideas on man's psychology perception and the aesthetic value itself convinced us of the beauty's objectivism.

- Michelangelo Buonarroti (1475-1564): He was an objectivist aesthetician and said that the form already existed in the matter before producing the object (Tatarkiewicz, 1978c:p.228). The beautiful is the arts' object, light and mirroring. For Michelangelo, the beauty was a quality owned with supremacy by nature (Gilbert and Kuhn, 1972:p.172), because God created the latter (Tatarkiewicz, 1978c:p.221), but the art models must be selected. He continued by saying that nature had a perfect beauty that the artist was not capable of reproducing entirely. He partly contradicted himself, adding that the artist could create works more beautiful than the natural ones (Tatarkiewicz, 1978c:pp.222, 223). Michelangelo's view leads us to the idea that nature is beautiful because God created it good. By creating it perfect, he put in it beauty. Also, when God created man, He added a similarity with Him, including the ability to create objects with his hands and He gave him creativity and originality - the necessary skills for man to produce, as a premeditated act, beautiful things.

- Descartes (1596-1650): He introduced the spirit of the method into art, "rational evidence and clarity". He diminished the role of imagination and sensory in art (Achiței et al., 1972:p.92). Descartes believed that beauty and grace were due to the parts' agreement and moderation (Gilbert and Kuhn, 1972:p.183). He was a subjectivist and argued that art was the subjective product of the imagination. The artistic and beautiful pleasure are subjective realities of the observer. These reactions depend on each person's taste and the mental image that that thing projects in each observer, based on his past experiences, his physical and mental state (Tatarkiewicz, 1978d:p.134). For a thing to be perceived beautiful, it must produce a positive sensory experience, be an intellectual (aesthetic) challenge for the observer, produce a mental pleasure through emotions (Tatarkiewicz, 1978d:pp.132, 133). Descartes mentioned two revolutionary aspects: firstly, that every man perceives differently the same beautiful object. This leads to the conclusion that the perception of beautiful depends on the subject, and that perception is itself different from the beautiful. Secondly, the perception of the beautiful is a source of psychological nurture: beautiful things hold a proper amount of intellectual stimulus for the subject.

- Alexander Baumgarten (1714-1762): He introduced the term aesthetics among the independent philosophical disciplines (Gilbert and Kuhn, 1972:pp.261-266). Hammermeister claimed that Baumgarten defined the aesthetics, in his work Aesthetics in 1750, as the science of the sensual knowledge (Hammermeister, 2002:p.4), which was essential to the rational knowledge (Hammermeister, 2002:p.7). He added that the natural, instinctive skills of feeling the beautiful can be trained so to transform into artistic thinking of the beautiful (Hammermeister, 2002:p.9). He agreed to the classical theory of the beautiful, consisting of unity and harmony (Hammermeister, 2002:p.11). Through Baumgarten's contribution, aesthetics was defined as the science of sensual knowledge, art theory, inferior knowledge through the senses, the art of the thought of the beautiful, and analogous art of the rational thinking (Hammermeister, 2002:p.9, 11). It is precipitate to believe that only what the observer feels to be beautiful is so. The observer may be insufficiently developed. Training the natural skills for detecting the beautiful is a learning process through which he evolves. The beautiful exists, it is present and persistent, but the observer must overcome their primary state to feel it.

- Immanuel Kant (1724-1804): He divided the beautiful into two categories: the free one - purpose-free, superior, whose supreme model is the human body and the adherent beautiful - which has a purpose or a utility. (Hammermeister, 2002:pp.25-26). Considering the good and the beautiful synonyms was a mistake of aesthetic judgment for Kant (Hammermeister, 2002:p.27). He offered four definitions of beautiful as follows:

1. Beautiful is based on quality, it refers to the feeling of pleasure or unpleasure that it creates to the 
observer, without pursuing any benefit or any utility from that. Kant was a subjectivist aesthetician.

2. Beautiful is subjective if its pleasure comes from taste, respectively objective if it comes from the universal appraisal.

3. Beautiful is the form of utility without purpose, without any end.

4. The beautiful universally likes without having a purpose (Hammermeister, 2002:pp.29-32).

Kant was a subjective aesthetician and emphasised the mass appraisal of the beautiful's value, which may be a trap if the mass is not cultivated or prepared enough to identify and appreciate what is beautiful.

- Georg Wilhelm Friedrich Hegel (1770-1831): He emphasised the difference between the beautiful and the ugly or industrialised objects of art (Hammermeister, 2002:p.90). Hegel believed that the observer had a particular culture and consciousness, which he identifies the beautiful things around him with, using models of the previously conscientious beauty (Hammermeister, 2002:p.93). The artistic beauty was complemented by religion and philosophy, and it had the role to conscientise and to express one's self (Hammermeister, 2002:p.94). Hegel defined the beautiful as "the sensory appearance of an idea" [das sinnliche Scheinen der Idee], the association of an object with a concept (Hammermeister, 2002:p.95). He contradicted the mimesis theory as he noticed that what is ugly can be mimicked too. We add that for the human to have a consciousness of the beautiful which, if not born with, they must acquire it, and if they were born with it, then it must be discovered through meditation. Both the acquisition of the consciousness of beautiful and the meditation to discover the beautiful from one's self are the continually improving result of the process of assimilation of concepts and phenomena to create a mental map. What comes from Hegel's conception and sustains our theory of beauty is that it needs to rely on a concept of what is beautiful, a concept from which and to which runs a cycle of discovery-definition processes until the exhaustion of the rationality and the creativity of the value judgment.

- Charles Baudelaire (1821-1867): He mentioned that by studying the history of beauty, one would notice that the same essence takes different forms throughout the ages. Baudelaire observed that the human's ability to create beautiful things is reflected in their appearance and gestures, even in the features of their face, starting to resemble what they would want to be with (Baudelaire, 2004:p.4). By virtue of the inertia to resist, to persist, to continue, beauty found its way to appear in each era. Baudelaire proposed a rational and flowing theory along with the history of beauty, saying that the beautiful is made up of an eternal, invariable core element and a relative, conjunctural element presented in a comprehensible shape for humans (Baudelaire, 2004:p.4). Regarding Baudelaire's definition of the beautiful, we continue to speculate on the identity of this eternal element, trying to argue that this is the level of personal human evolution, from any position be it artist, critic, observer or society taken as a whole.

- Alain (1868-1951): He brought into the discussion some aspects of logic in the value judgment, as they follow. Everyone justifies his value judgment on beauty according to their taste or pleasure (Alain, 1920:p.8). The beautiful work must not be proven by others to be beautiful, for it defends its beauty by itself (Alain, 1920:pp.9, 10). It is bound to meditation without which the issuing of value judgments are simple decisions of belonging to an opinion group or another (Alain, 1923:pp.54-55). He also added that what was beautiful was immediately recognised by the public and gained general recognition (Alain, 1920:p.9). It seems very plausible to us that the beautiful is part of human nature, it is an ability that, similar to intelligence or the skill to do something, is practised, learnt, improved, discovered, meditated on to understand increasingly profoundly. According to the depth that the understanding of beauty has reached, it also shows up one's ability to identify and produce it.

- Wladyslaw Tatarkiewicz (1886-1980): A statement of his vision on the beauty prioritises the aesthetic experience as a result of the authentic reception of artistic creation. An interesting idea of his is that the artist is evaluated for the aesthetic qualities of his works. Artworks are evaluated as perfect only extremely rarely, but nature or the human body benefited from this qualifier often, being taken as models of the artistic creation (Tatarkiewicz, 1972:p.169). If nature is again qualified as perfect, then Who made it has a creative brilliance that may have been passed on to humankind, who can focus their efforts to discover their aesthetic abilities and utilise them. 
Tatarkiewicz helped us to conclude that once humankind has an overview of what beauty is, they start climbing these steps:

1. identifying the components of things and studying their traits;

2. stating definitions of beauty either related to its components or the features of things, reaching a definition preferred by the majority;

3. identifying the impacts of the aesthetic qualities of things on the observer and analysing these impacts;

4. phrasing metaphysical and abstract definitions related to the aesthetic experiences of the subject;

5. identifying the bridge between the beautiful object and the level of assimilation of beautiful that the subject reached.

- Martin Heidegger (1889-1976): He was a subjectivist aesthetician philosopher. The beautiful, for him, was identified by the aesthetic perception (Hammermeister, 2002:p.174). He defined the beautiful as a way of revealing the truth (Hammermeister, 2002:p.183). The beautiful is a language of expressing the truth, a language that requires considerable effort to be decrypted. The effort to optimise the language, which the truth reveals the beauty through, as inspired by Heidegger, comes to support our theory because we believe that humans are only able to understand the beauty when enough effort is made to understand its language, the way it expresses without words, through pictures, and shapes. For that, one must also have the language developed enough to help them express the description, the definition and the evolution of beauty.

- Mikel Dufrenne (1910-1995): He said that beauty characterised the aesthetic objects and that beauty is the specific (Dufrenne, 1973:p.58), supreme and exclusive aesthetic quality (Dufrenne, 1973:p.59). He added that the beauty of an aesthetic object must not be endlessly demonstrated, because it merely exists in that object (Dufrenne, 1973:p.58). Dufrenne considered that beauty included harmony, purity, nobility, serenity, sealing the authentic artwork (Dufrenne, 1973:p.59). Beauty consists in the truth revealed by a thing that manages to display its qualities, generating in the observer emotions and feelings of fulfilment thanks to the harmony between imagination and understanding (Dufrenne, 1973:p.61). He noticed that beauty is found in that previously defined aesthetic thing, while the observer plays the role of becoming aware of it (Dufrenne, 1973:p.62). The extent to which the observer discovers beauty in things depends on their taste, culture and own nature (Dufrenne, 1973:p.63). Separating the beautiful from the truth, Dufrenne argued that the effort to find the truth was more significant, assiduous and could also lead to negative effects, while beauty had positive effects (Dufrenne, 1973:p.428). We appreciate Dufrenne for being an objectivist aesthetician and bringing into sight that humankind needs to understand the beauty that exists.

- Monroe Beardsley (1915-1985): Beautiful is a perceptual quality, variable in intensity and hard to perceive (Beardsley, 1962:p.624), and, thus, each of us could define it according to one's aims. Beardsley defined it through these statements.

1. "The beautiful is a perceptible quality, and any artistic property that cannot be perceived is anything else but the beauty" (Beardsley, 1962:pp.624-625).

2. Beauty is the quality of some or all of the parts of a whole complex, where the whole creates a context.

3 . Beauty is a simple quality that characterises a complex (Beardsley, 1962:p.625).

4. The level of beauty of a thing assigns its own aesthetic value and can be given by fulfilling some alternative conditions such as consistency, fullness, a minimum level of complexity conferred by "subtlety and richness of significance".

5 . Beauty is not a necessary condition of the aesthetic value (Beardsley, 1962:p.626).

As per Beardsley's first definition of beauty, we notice that he is a subjectivist aesthetician. He moves away from the essence of the beauty when he validates the beauty in an object through the observer's ability to perceive it. It is obviously a trap to label the object according to the subject's abilities. We agree with Beardsley that beautiful is a complex of traits, and also that we often define it according to our needs and goals.

- Umberto Eco (1932-2016): He said that humans had been preoccupied instinctually by the beautiful, looking for pleasure, because it is a primary necessity for them (Salvatore and Pagani, 2012). Beauty was also a matter: of taste, thus of choice; of habit or of belonging to a culture; of a stage in the evolution of the human civilisation; of standards owned at a certain point in time (Salvatore and Pagani, 2012). 
Beautiful is a relative concept, while ugly is a less relative one. One replaces the beautiful with the ugliness when the traditional values cannot satisfy their aesthetic needs (Salvatore and Pagani, 2012). Beautiful is part of an artwork that serves its purposes (Salvatore and Pagani, 2012). The explanation of the beautiful phenomenon, as Umberto Eco also noticed, takes place at a profound, instinctual, primary, primordial level of our being. The reason why beauty has its roots here drives us to the idea that the beautiful had existed in the human before they realised it. It remains that humans, through their life experience, there deeper and deeper preoccupations of what life is, including what beautiful is, and the continuous effort to evolve, to go down to the concept of beauty to identify and produce it. As Eco suggested too, the consequences of the beautiful are positive, and the good is an extension of the beautiful. If the consequences of a thing are negative, it was not beautiful.

In Fig. 1, this set of 23 theories and views on the beautiful are laid down.

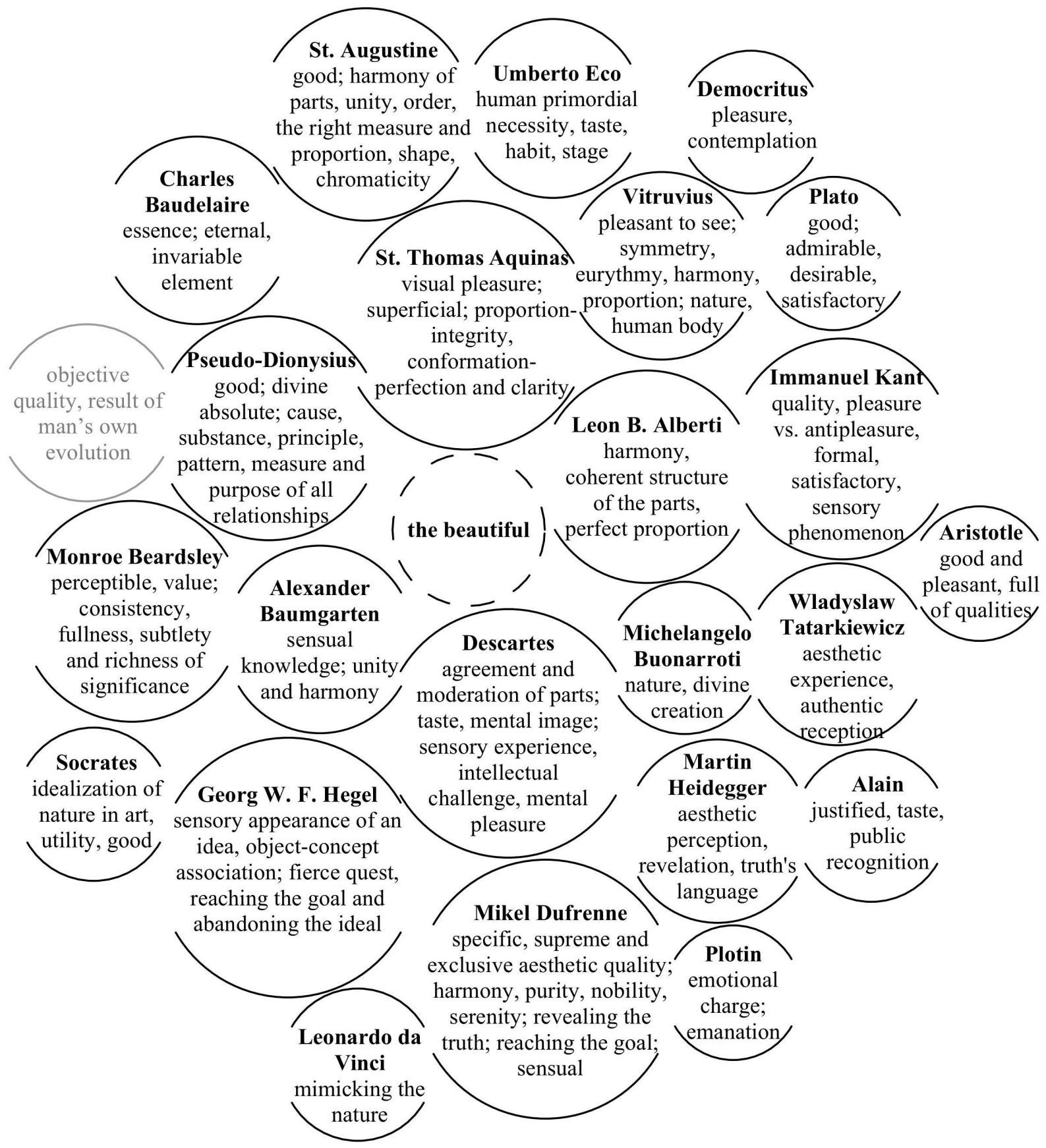

Fig. 1 The scheme of theories and views on the beautiful from a series of thinkers and aestheticians 


\section{Conclusion}

Centuries of practice and meditation on beauty have led to an essential psycho-philosophical and emotional conclusion: beautiful is the synthesised impression of what resembles the original element emanator of emotions and impressive sensations.

Perhaps due to a greater closeness to nature, due to an incomparably lower technological advance in comparison to what is offered today, or due to the acute persistence of the struggle to satisfy the primary physiological and security needs, humans felt the need to regain the beautiful, besides an expression of their culture and psychology, the comfort from good, of the positive, which supplemented some of the shortcomings they were suffering.

\section{References}

Achiței, G., Breazu, M., Ianoşi, I., Maşek, V. E, Pascadi, I., Rusu, L., Smeu, G., Sommer, R., Stroia, G., Suchianu, D. I. (1972) "Dicţionar de estetică generală" (Dictionary of General Aesthetics), Politică, Bucharest. (in Romanian)

Alain (1920) "Système des beaux-arts" (The Fine Arts System), Gallimard, Paris, France. (in French)

Alain (1923) "Propos sur l'esthétique" (On the Aesthetics), Stock, Paris, France, pp. 54-55. (in French) https://doi.org/10.1522/cla.ala.pro7

Basch, V. (1930) "Essai critique sur l'Esthetique de Kant" (Critical Essay on Kant's Aesthetics), The Neo-Scholastics Philosophy Review, 32(27), pp. 377-378. (in French)

Baudelaire, C. (2004) "The Painter of Modern Life and Other Essays", translated by Mayne, J. (ed.), Phaidon Press, London, UK, p. 4. [online] Available at: http://baudelaire.litteratura.com [Accessed: 10 February 2017]

Beardsley, M. C. (1962) "Beauty and Aesthetic Value", The Journal of Philosophy, 59(21), pp. 617-628. https://doi.org/10.2307/2023283

Dufrenne, M. (1973) "The Phenomenology of Aesthetic Experience", Northwestern University Press, Evanston, IL, USA.

Gilbert, K. E., Kuhn, H. (1972) "Istoria esteticii" (The History of Aesthetics), Meridiane, Bucharest, Romania. (in Romanian)

Hume, D. (1742) "Essays, Moral and Political", A. Kincaid, Edinburg, UK.

Hammermeister, K. (2002) "The German Aesthetic Tradition", Cambridge University Press, Cambridge, UK. https://doi.org/10.1017/CBO9780511613883

LatteralMente "Le Frasi più Belle di Umberto Eco" (The Most Beautiful Phrases by Umberto Eco), [online] Available at: https://letteralmente. net/frasi-celebri/umberto-eco.php [Accessed: 25 February 2017] (in Italian)
Beauty accomplishes the same thing every time; it completes the complex of features of human expressiveness.

As will be presented in the article that will be published soon as the second part of this Reconsideration on the Theory of Beauty, humans pass through these stages of confirmation, interruption and reconsideration, refutation, combat of the previous phases, recall, rediscovery and redefinition of the beautiful continuously. All these stages, that apparently the concept of beauty crosses over, are stages of evolution of human thinking. Because not every person passes through all of these stages, it is expected for them to forget from time to time the phases their predecessors have crossed already, and this compels them to repeat history until the integrated assimilation of their aesthetic heritage.

Maslow, A. H. (1943) "A Theory of Human Motivation", Psychological Review, 50(4), pp. 370-396. https://doi.org/10.1037/h0054346

Moldovan, M. S. (1993) "Curs de estetică" (Aesthetics Lecture), UTPress, Cluj-Napoca, Romania. (in Romanian)

Morar, V. (2003) "Estetica. Interpretări şi texte" (Aesthetics. Interpretations and texts), Universităţii din Bucureşti, Bucharest, Romania. (in Romanian)

Plato (1976) "Opere II" (Works II), Ştiinţifică, Bucharest, Romania. (in Romanian)

Romanian Academy, Iorgu Iordan Linguistics Institute (2000) "Dicţionarul Explicativ al Limbii Române" (Explanatory Dictionary of Romanian), Univers Enciclopedic, Bucharest, Romania. (in Romanian)

Salvatore, F., Pagani, E. (2012) "Bruttezza e bellezza secondo Umberto Eco" (Beauty and Ugliness according to Umberto Eco), PanoramItalia Review, [online] 02 October 2012. Available at: www.panoramitalia.com [Accessed: 25 February 2017] (in Italian)

Tatarkiewicz, W. (1972) "The Great Theory of Beauty and Its Decline", The Journal of Aesthetics and Art Criticism, 31(2), pp. 165-180. https://doi.org/10.2307/429278

Tatarkiewicz, W. (1978a) "Istoria esteticii" (The History of Aesthetics), Meridiane, Volume I, Bucharest, Romania. (in Romanian)

Tatarkiewicz, W. (1978b) "Istoria esteticii" (The History of Aesthetics), Meridiane, Volume II, Bucharest, Romania. (in Romanian)

Tatarkiewicz, W. (1978c) "Istoria esteticii" (The History of Aesthetics), Meridiane, Volume III, Bucharest, Romania. (in Romanian)

Tatarkiewicz, W. (1978d) "Istoria esteticii" (The History of Aesthetics), Meridiane, Volume IV, Bucharest, Romania. (in Romanian) 